\title{
Reflection of Time in Postmodern Literature
}

\author{
By Tatyana Fedosova*
}

This paper considers key tendencies in postmodern literature and explores the concept of time in the literary works of postmodern authors. Postmodern literature is marked with such typical features as playfulness, pastiche or hybridity of genres, metafiction, hyperreality, fragmentation, and non-linear narrative. Quite often writers abandon chronological presentation of events and thus break the logical sequence of time/space and causeleffect relationships in the story. Temporal distortion is used in postmodern fiction in a number of ways and takes a variety of forms, which range from fractured narratives to games with cyclical, mythical or spiral time. Temporal distortion is employed to create various effects: irony, parody, a cinematographic effect, and the effect of computer games. Writers experiment with time and explore the fragmented, chaotic, and atemporal nature of existence in the present. In other words, postmodern literature replaces linear progression with a nihilistic post-historical present. Almost all of these characteristics result from the postmodern philosophy which is oriented to the conceptualization of time. In postmodernism, change is fundamental and flux is normal; time is presented as a construction. A special attention in the paper is paid to the representation of time in Kurt Vonnegut's prose. The author places special emphasis on the idea of time, and shifts in time become a remarkable feature of his literary work. Due to the dissolution of time/space relations, where past, present, and future are interwoven, the effect of time chaos is being created in the author's novels, which contribute to his unique individual style.

Keywords: Postmodern Literature

\section{Introduction}

Time, being a significant component of life in the universe, has excited the minds of many thinkers throughout many centuries. It has been an endless source of perplexity mostly due to its elusive nature. The works which have come to us of such philosophers as Heraclitus, Aristotle, and Augustine are devoted to this issue, fundamental theories of the 19th and 20th centuries are connected with it, and the advanced achievements of scientists directly or indirectly touch upon the concept of time. Notwithstanding the technological progress and advancement in studying the category of time, it continues to remain one of the unknown phenomena in which 'the central problem of all ontology' is rooted. As A.P. Levich (2009) notes, the causes of the emergence of changes and creation of the new in the World (the nature of time) is the greatest enigma of science.

Today researchers point out different aspects of time: physical, biological, social, historical, objective, subjective, linguistic, etc. Time becomes not just a subject of philosophic reasoning, but an object of serious scientific research.

${ }^{*}$ Associate Professor, English Department, Gorno-Altaisk State University, Russia. 
The following facts support this point of view: in 1966 J.T. Fraser founded the International Society for Study of Time, which marked a special stage in the development of temporal studies and which is characterized by the interdisciplinary approach to time as to the object of the scientific analysis, and in 1984 the Interdisciplinary seminar on research of the phenomenon of time was established at Moscow State University. There appears a new term temporality, i.e. time as a unity of the past, the present and the future.

The postmodern paradigm is characterized by a refusal of rules and norms, a mode of expenditure, playfulness, entertainment and free leisure. The objective of the modernist style was economy and time planning, and the postmodern primary factors are activation of intercultural contacts, virtual reality, and neglect of norms and canons. Moreover, time from a cultural category turns into a personal category which finds its reflection in creativity of postmodernists and in the text as a creative product.

Nowadays, people express courageous assumptions that the world is generated by time movement. However, in our opinion, time as one of the dimensions, is given to people for convenience, so that they could have sequence and orderliness in thoughts and actions. In a similar way, time in written texts also works for ordering the events and actions of characters. The textual time has much in common with the objective time, but also possesses unique characteristics. The temporal structure of the text is a certain model which is formed by means of the organization of events in the text with the help of the means for expressing time.

In this paper, the author tries to reveal the features of a postmodernist paradigm by means of time analysis in modern literary works, the descriptions of writers' views on the given phenomenon, and the reconstruction of 'an author's picture of time.' An individual author's temporal picture grows out not only from the integration of cultural models of time existing in a society, but also the personal temporal experience and time comprehension (ego-based and time-based models). The conceptual system of the author including his/her temporal picture is projected in his/her products. A typical feature of postmodern authors is the individual treatment of a category of time which sometimes is only implicitly present in texts, but also in this case it is possible to see the regularity in its expression and representation, and on this basis to define a postmodern manner of writing.

\section{Basic Features of Postmodern Literature}

Postmodern literature is presented by such key figures as J. Bart, U. Eco, K. Vonnegut, J. Fowles, T. Morrison, M. Atwood, etc. Postmodern texts are marked by the mixture of times, cultures, languages, real facts and fiction, the present and the past. The attempts to single out the basic features of postmodernism were undertaken by different researchers. However till now there is no strict classification of means of the organization of the postmodern text. 
Let's mention only some fundamental postmodern principles: rejection of strict rules of a plot construction; the ironic attitude to reality; a discourse fragmentariness; collage; montage; hybridity of genres; paradoxicality; playing with the text, with time, and with the reader; intertextuality; citation; pluralism of styles; a multilevel text organization; orientation at the plurality of text interpretation; a principle of reader's co-authorship, etc. The narrative conventions are often ignored. In literature and cinema, playing with time becomes one of the main devices with the help of which unique and original narrative courses, such as travel in time and time shifts are created.

One of the essential aspects of postmodernism is the reflection on the following question: what is reality? The following conclusion is made: everyone has his/her own reality and everything accepted for reality is only a representation of it, and language does not only express reality but also creates it (Brockmeier, 1994). That is to say there is no way of knowing reality as it really is, independently of the structuring framework that conditions how the world appears to us.

In a similar way text and time are treated. The text in postmodernism represents the structure consisting of a set of other texts. Time represents a certain construction which is formed by a personality. Thus it is perceived differently by different people. Writers pay special attention to the personal experience of time, describing various temporal experiences. P. Rosen (2001) compares modern temporality to a battlefield: Modern temporality is like a battle terrain on which the disordering force of time struggles with the need and desire to order or control time.

In literature of the given direction there is a tendency to the so-called narrative chaos. Writers intentionally break off a chronological narration with reminiscences of characters or prospection. Thus, U. Eco (2007) in the novel Baudolino constantly devotes the reader into what will occur to this or that character in the future. For example, Nikita has seen his own death, Baudolino relates that he has killed the murderer of king Frederick Barbarossa when the king is still alive, the story of Baudolino looks as fragmentary as the novel's characters, etc. This device creates the effect of an intrigue, internal tension, and unexpectedness.

Tony Morrison's novel Jazz also abounds in reminiscences and lyrical digressions. The heroine Violet tries to put together evidences about a dead girl Dorkas who was her husband's mistress. In the novel, there is a returning from the present to the past, to the moment of the girl's funeral where Violet created a scandal: She is awfully skinny, Violet; fifty, but still good looking when she broke up the funeral (Morrison, 1970). Throughout the novel, Violet wants to restore the past in order to learn and understand why Dorkas attracted her husband. The presence of two temporal planes is expressed by the use of two verbal forms - the present and the past tenses. 


\section{Primary Properties of Objective Time and Text Time}

Time possesses a few important properties which have a different nature in the text. Firstly, it has the ability to set events in order, its continuity and one way orientation. Its next characteristic is variability, fluidity, movement from the past to the future. Here appears an image of time as a river into which it is impossible to enter twice: Time is like a river made up of events. No sooner does anything appear than it is swept away and something else comes into its place. The swiftness of a time flow changes with the variation of speed of movement; now there is proof (experiences with an atomic clock) of nonuniformity (variation) of a time flow. Scientists speak about a cyclic character of time: natural cycles, historical cycles, in economics Kondratyev's cycles are known; in the world there is a repetition of the phenomena and processes. In other words, the events on the planet will always repeat themselves and so will the events in time.

Another major property of time is its objectivity and subjectivity. It is subjectively formed for each person differently under the influence of different factors (world outlook, age, etc.) but it is also psychological, i.e. it depends upon personal aspects and situations and exists at the level of consciousness, perception, and feelings. In the case of brain damage, consciousness frustration, or depersonalization, there is a distortion of time perception, a feeling of loss in time, it seems either too slow, or too fast which is often accompanied by unreality of the experienced situation.

These phenomena of bifurcation of consciousness and inadequate perception of time become the subject of plots of modern writers. Thus, in the works of Russian postmodern writer, Victor Pelevin, there are shifts in time due to the shifts in consciousness of characters. In Omon Ra, under the influence of soporific, the main character experiences memory blackouts, hallucinations; movement from one time interval into another, from one space (Moon) to another (Earth) are observed (Pelevin, 2001).

In the novel Chapayev and Pustota time becomes the principal subject of reflection for the protagonist, and the author himself: whether I exist thanks to the world, or the world exists thanks to me. There is always the thought of what is real and what is not, life is a dream, the world is a mirage and that it is not easy to get to the future: It has suddenly come to my mind that from the beginning of times I have simply been lying on the bank of the Ural and I have dreams replacing each other, again and again I wake up here (Pelevin, 2007). Due to a turbidity of consciousness, impaired judgments, false personalities, effects of schizophrenia, and sessions of psychotherapy the hero alternately turns out to be at the beginning of the 20th or 21st centuries. Because of wounds, the hero has memory blocks; therefore he keeps a diary where he writes down necessary information, then re-reads it, and tries to recollect everything. V. Pelevin uses special cinematographic effects, montage, and combined shootings, the method 'a story in a story'; the steam locomotive serves as a symbol of time. 
In consciousness, and, hence, in the text as its product, the category of time has a more difficult structure, a wider range and a more voluminous, unreal plane. The literary world represents a complex, multiplane construction with a narrative structure and a story line, where the objective characteristics of time are transformed. Time becomes unsteady, diverse, and reversible. Text time (story time, the time of narration) is multidimensional and discrete, retrospective and prospective, unsteady and unstable. Shifts in time also cause shifts in space which is reflected in M. Bakhtin's theory about chronotope, as a unity of time and space.

The 20th century brought literary texts which one can read from any page; novels without endings, 'the beginning starting in dénouement (resolution) or 'alternative endings' are quite popular. For example, V. Nabokov's story (1936) The Circle begins with the words: Secondly ... and ends: Firstly... Travelling back in time gives the possibility that one can encounter oneself, as in the story by J.L. Borges The Other, where Borges meets himself in the past as a young man (Borges, 1967).

In the novel, at the author's will, events can change their order, move from the end to the beginning, step over certain intervals and stages, stop, freeze, stretch or compress. They can even disappear and at the author's will, appear again. U. Eco, in the novel Foucault's Pendulum (1988), shows that a narrator prints the text on the computer, then deletes it because wanted, that what I have written, never would happen. The text disappears, but it can be easily restored in the computer by pressing a necessary key.

J. Updike's The Centaur (1991) represents a bright illustration of an interlacing of the real and unreal, myths and autobiography where the author uses original ways of the story organization: mythological allusions, transitions from one literary world to another, reminiscences, internal monologues, and polyphony. At the beginning, it is difficult for the reader to understand when an action takes place: in 1947 or a few years later, the hero of the novel appears on its pages after the reader has seen the obituary devoted to the protagonist.

Russian female writer Dina Roubina (2008) in the novel On the Sunny Side of the Street, touching upon a question of mutual relation of the person and time, names the latter 'bottomless waters' and 'a shapeless substance escaping, departing away full of holes as shreds of a fog, which can be calculated and broken into smallest parts, and also describe all smallest movements during these instants, but it is impossible to fathom and to keep.

Modern researchers pay special attention to the present: It's all Now, you see. Yesterday will not be over until Tomorrow, and Tomorrow began ten thousand years ago (Faulkner, 1948). According to J.L. Borges (1948), the present always has a particle of the past, a particle of the future. V. Pelevin's character said: I know for a long time already that the unique real instant of time is "now" (Pelevin, 2007). The "now" phenomenon cannot exist in physics without generating a paradox between a causal determinism and a continuous change (Sanfey, 2003). J. Fowles (1998) writes: 
I was trying to emphasize the importance of the now. The nowness of any given point in time is pure and virginal. You do not begin to understand ordinary history until you have at least some sense of this staggering perpetual yet evanescent nowness.

\section{Metaphorical Conceptualization of Time}

Writers often resort to the symbolical and metaphorical representation of time. Time can be perceived, measured, and described in the text. Lingual signs have huge potential to express time; in languages there is a large amount of metaphorical and idiomatic expressions with a time attribute, and native speakers possess a rich palette of language means and ways for the reproduction of temporally marked statements.

Temporal categorization includes two dominant aspects: perception of time and its semiotization (accentuation of key properties and their conceptualization), and also the choice of a lingual sign with the help of which the time component in a described fragment of reality is adequately reflected. The perception of time occurs in a greater degree by means of language. Also existing are pre-linguistic cognitive structures, gestalts, frames, operating with an organic part of speech origination.

Conceptual metaphors transferring the representations about time can be divided into the following groups: Time is a live being (it reigns, corrects, heals, demands, runs, flies, goes, marches on, time waits for no one etc.) and Time is an inanimate object (a river, a wheel, a fire, water, mirror etc.). Time is often presented in literary texts in the form of various constructs, images, and comparisons. The works of the English postmodernist author Angela Carter serve as a vivid example of this fact. The watch and clock have obviously a deep meaning for A. Carter for the clock quite often becomes a symbol of time passing and a motif in her tales. In the novel Heroes and Villains the image of hours appears from the first page:

Marianne had sharp, cold eyes and she was spiteful but her father loved her. He was a Professor of History; he owned a clock which he wound every morning and kept in the family dining-room upon a sideboard full of heirlooms of stainless steel such as dishes and cutlery. Marianne thought of the clock as her father's pet, something like her own pet rabbit, but the rabbit soon died and was handed over to the Professor of Biology to be eviscerated while the clock continued to tick inscrutably on. She therefore concluded the clock must be immortal but this did not impress her. Marianne sat at table, eating; she watched dispassionately as the hands of the clock went round but she never felt that time was passing for time was frozen around her in this secluded place where a pastoral quiet possessed everything and the busy clock carved the hours into sculptures of ice. (Carter, 1970) 
For the teenage girl, time lasts painfully long since she has no interesting occupation, time has fallen asleep and does not move, although the clock has not stopped, it counts hours which then turn into ice sculptures. Getting into an absolutely different world of barbarians, the heroine senses a difference in perception of the flow of time:

If time was frozen among the Professors, here she lost the very idea of time, for the Barbarians did not segment their existence into hours nor even morning, afternoon and evening but left it raw in original shapes of light and darkness so the day was a featureless block of action and night of oblivion. (Carter, 1970)

The clock symbolizes time in the text which the following excerpt proves:

She wore a dead wrist watch on her arm, purely for decoration; it was a little corpse of time, having stopped for good and all at ten to three one distant and forgotten day (Carter, 1970).

The clock also passes as a visible line in other A. Carter's books: 'When we were just babbling our first ' $g$ 'anma ', that clock turned up' (Carter, 1991). In the novel The Magic Toyshop time has stopped for the heroine Melanie, when she had to move to unfamiliar relatives after her parents' death. For the first time in many months, already at the end of the novel time has revived, moved quickly, and here again we see the clock:

He raised his arm, took aim and flung the mug at the cuckoo clock.

The little door spurted open. The cuckoo came out and chanted fourteen o'clock, fifteen o'clock, sixteen o'clock. (Carter, 1967)

In fiction we come across various images of time. Some of them are very individual and unique, others are more traditional. Images of time comprise various characteristics and patterns. In many examples there is a semantic transfer of a general philosophic concept of time to an individual perception of time.

\section{Time in Kurt Vonnegut's Prose}

Most novels of contemporary American writer K. Vonnegut are autobiographical and present a collage. They connect reality and fantasy, fiction and documentary facts, logic and absurdity. Frequently Vonnegut's works have the same characters. The principle of text coherence is broken in his fiction: Vonnegut's characters for a certain period of time get to different places (Slaughterhouse-Five, The Sirens of Titan), and, being in one place, they can stay in various time planes (Timequake). 
Time frameworks in the novel The Sirens of Titan are defined by the author as follows: The following is a true story from the Nightmare ages, falling roughly, give or take a few years; between the Second World War and the Third Great Depression (Vonnegut, 1998b). For the reader these frameworks are half fantastic, half realistic which gives the impression of a total timelessness of events and insignificance of time borders and a consecutive course of events in the novel. However, developing the novel's events on a universal scale, the author gives concrete time indications which makes the reader believe in the validity of the story: It was a Tuesday afternoon. It was springtime in the northern hemisphere of Earth, 67 Earthling days, 2 minutes before start, 59 days later, etc. (Vonnegut, 1998b). The author also provides detailed descriptions the metrization of time on Mars which makes the story true to life:

The Martian year was divided into 21 months, twelve with thirty days, and nine with thirty one. These months were named January, February, March, April, May, June, July, August, September, October, November, December, Winston, Niles, Rumford, Kazak, Newport, Chrono, Synclastic, Infundibulum, and Salo. The length of a year on his home planet, according to his own calculations, was 3.6162 times the length of an Earthling year - so the celebration in which he participated was actually in honor of a government 361,620,000 Earthling years old (Vonnegut, 1998b).

Vonnegut's novel Timequake, the title of which is the author's neologism, is rich in variations of time changes. The title itself comprises the idea of heterogeneity of a current of time, its displacement, and transposition. In the novel's prologue the definition of 'a timequake' is given: '... a timequake, a sudden glitch in the space-time continuum ...' (Vonnegut, 1998a). The novel narrates about a science fiction writer Kilgore Traut. The author shows two story lines which constantly intertwine: in 2001 Traut is a recognized writer who has arrived at the conference, and in 2010 he is a person without any means of livelihood.

Even though there is no chronological order of events in his books, each text has a starting point of orientation. In this novel, all events are presented from the point of view of the author's present, i.e. 1996 is a narration starting point: Those speeches, those situations, those people became emotional and ethical landmarks for me in my early manhood, and remain such in the summer of 1996 (Vonnegut, 1998a). In 2001 there is a sudden shift in time, it shrinks, turns back, and everything repeats itself from 1991 till 2001: It suddenly shrank ten years. It zapped me and everybody else back to February $17^{\text {th }}, 1991$ ... (Vonnegut, 1998a). Then the author describes 2010 and tenses also move from the past to the present:

It is like a birthday present from my computer here in Sinclair Lewis Suite at Xanadu. Wow! The date yesterday was November 11, 2010. 
I have just turned eighty-eight, or ninety-eight, if you want to count the rerun (Vonnegut, 1998a).

Such a disorder in time is a typical, individual feature of K. Vonnegut. The reader should work hard to build a chronological outline of the text. In the prologue to Timequake the author admits that all time shifts occur randomly:

In chapter forty-six, I imagine myself as still alive in 2010. Sometimes I say I am in 1996, where I really am, and sometimes I say I am in the midst of a rerun following a timequake, without making clear distinctions between the two situations (Vonnegut, 1998a).

When reading this novel-"labyrinth" the impression of a cinematographic effect is created, the tape rewinds, people come back to former places where they were exactly 10 years ago:

... everybody and everything were exactly where they had been when the timequake struck. So Zolton was paraplegic again in a wheelchair, ringing the doorbell again ... Monica was working on the budget for Xanadu when the timequake struck (Vonnegut, 1998a).

Instant change of existential coordinates is a predominant device in Slaughter-House Five. The protagonist of the novel Billy Pilgrim is in Germany during World War II and simultaneously travels to the planet of Tralfamador where he discovers a tremendous nature of time: ... everything that ever has been always will be, and everything that ever will be always has been (Vonnegut, 1999). This discovery has something in common with the biblical verse: 'Whatever is has already been, and what will be has been before' (Ecclesiastes 3:15). The same idea the author puts into the words of one of the characters in The Sirens of Titan: Whatever we've said, friends, we're saying still - such as it was, such as it is, such as it will be (Vonnegut, 1998b). Thus, this idea has been developed by the author throughout several years.

K. Vonnegut does not limit either temporal or spatial borders in his books. The plots of his novels occur in different time periods (the Second World War, 2016, the far future, the second half of the 20th century), in the limits of and outside the Solar system. Vonnegut's personages easily (in their sleep, by means of radio-waves and UFOs) move from Earth to Mars, Mercury, Titan, and Tralfamador (The Sirens of Titan, Slaughter-House Five), some pieces of their life can be repeated, and they have a chance to live ten years of their life anew (Timequake).

The fragmentary discourse, composition randomness, the synthesis of different temporal planes, time compressions and ellipses connected with the 
expression of temporality of texts characterize Kurt Vonnegut's manner of writing and distinguish his style (Fedosova, 2006).

\section{Results and Discussions}

The notion of time is a complex one. In postmodernism there exists a similar view on reality, text and time which represents a set of individual realities, texts and times. The personal construction of time depends upon the cultural canon and moreover upon the personal sense emerging in the individual idiosystem. In this paper, there was an attempt to provide a brief survey of time and its representation by postmodern novelists and to outline various positions their works have engendered. The experimental data used in this study consist of postmodern literary texts. To our knowledge, no systematic study of temporal structure in postmodern discourse has yet been carried out and little attention has been given to this particular theme of postmodern writers. In general, the category of temporality manifests a correlation with the overall discourse structure. The postmodern time is something to be constructed, shaped, and reproduced.

Many writers prefer a progression without chronology, using the so-called polychrony, a heterogeneous temporality and chronological distortions (anachronies). For this purpose, they break the sequence, put things out of order, locate events from the present back into the past, describe a variety of temporal experiences, produce new experiences of time, temporal and causal relationships become indistinguishable. Sometimes due to anachronies the reader has difficulties with the reconstruction of the event pattern of the story tying them together and learning the overall pattern of the story. Notwithstanding the seeming temporal chaos there is still a starting point of narration, the so-called narrative now-point.

For example, Kurt Vonnegut takes us back to different events at different times. The writer interweaves several complex narrative strands that move back and forth in time while the reader links these strands together. Flashbacks are often employed by K. Vonnegut like in a cinematic style. Time becomes a series of accidental encounters and events. His novels are a primary genre in which experiments with and interpretations of time and change take place, they are examples of manifold temporal disparities. They seem to be chaotic, because they do not follow the cause and effect order of the ordinary timeline; however, the narrative's extraordinary structure and the jumps in time emphasize coherence. Each of his tales has its own way of understanding time; one thing is certain that all his novels possess a temporal diversity and multiplicity.

Thus it is possible to conclude that though time is a complex and a multilevel category and phenomenon as it is, it becomes even more complicated in people's minds. That is why there are so many diverse ways to express it in literary works. In analyzing the works of postmodernists it is necessary to note that time in the postmodern text is presented as a complex 
multilevel and multifaceted structure which testifies that this complex phenomenon becomes more complicated in a person's mind, and, hence, gets various forms of expression in the text, as a product of the mind. In search of the answer to this question and trying to understand this phenomenon, authors resort to games, experiences, and experiments with consciousness that complicate its nature even more. The above described features make the postmodern authors' manner of writing unique and original, contributing to and distinguishing their individual style.

\section{References}

Borges, J.L., 1948. Time. In: Borges Oral. Available at: http://www.chronos.msu.ru [In Russian].

Borges, J.L., 1967. The Other. In: Selected Non-Fiction (ed.) Eliot Weinberger. NewYork: Penguin Books.

Brockmeier, J., 1994. 'Translating Temporality? Narrative Schemes and Cultural Meanings of Time.' Public lecture presented at Collegiums in Budapest, Institute for Advanced Study. ISSN 1217-5811 ISBN 9638463104.

Carter, A., 1967. The magic toyshop. New York: Penguin Books.

Carter, A., 1970. Heroes and villains. New York: The Pocket Books.

Carter, A., 1991. Wise children. New York: Penguin Books.

Eco, U., 1988. Foucault's pendulum. Saint-Petersburg: Symposium. [In Russian].

Eco, U., 2007. Baudolino. Saint-Petersburg: Symposium. [In Russian].

Fedosova, T.V., 2006. A Temporal text structure as a component of the author's individual style. Monograph. Gorno-Altaisk State University. [In Russian].

Faulkner, W., 1948. Intruder in the dust. New York: The Modern Library.

Fowles, J., 1998. Wormholes. New York: Henry Holt and Company Inc.

Levich, A.P., 2009. 'What We Expect from Studying Time.' Journal on Time. Available at: http://www.chronos.msu.ru/old/EREPORTS/levich what.htm

Morrison, T., 1970. Jazz. New York: Plume (Penguin Books USA).

Nabokov, V., 1936. The Circle. In: Spring in Fialta and Other Stories. Berlin. Available at: http://nabokov.gatchina3000.ru/ [In Russian].

Pelevin, V., 2001. Omon Ra. Moscow: Vagrius. [In Russian].

Pelevin, V., 2007. Chapayev and Pustota. Moscow: Eksmo. [In Russian].

Rosen, P., 2001. Change mummified: Cinema, Historicity, Theory. Minneapolis: University of Minnesota Press.

Roubina, D., 2008. On the sunny side of the street. Moscow: Eksmo. [In Russian].

Sanfey, J.J., 2003. 'Reality and Those Who Perceive It.' In: The Nature of Time: geometry, physics, and perception. R. Buccheri, M. Saniga, W.M. Stuckey, (eds.) NATO Science Series. Dordrecht: Kluwer Academic Press.

Updike, J., 1991. The centaur. New York: Fawcett Books.

Vonnegut, K., 1998a. Timequake. Berkley: A Berkley Book.

Vonnegut, K., 1998b. The sirens of Titan. Berkley: Berkley Publishing Group.

Vonnegut, K., 1999. Slaughter-house five. New York: Dell Publishing Co. 
